\title{
Aspectos epistemológicos e pedagógicos da educação profissional e tecnológica: implicações para a prática docente
}

Caetana Juracy Rezende Silva

Ministério da Educação

Olgamir Francisco de Carvalho

Universidade de Brasília

Resumo: A inédita expansão na educação profissional e tecnológica ocorrida nas últimas décadas não foi acompanhada de ações suficientes voltadas à formação docente. Milhares de profissionais têm exercido o magistério nesse campo sem qualquer debate anterior sobre suas características e implicações para a prática docente. Há consenso quanto à falta de formação docente específica, particularmente para aqueles que atuam nas chamadas disciplinas técnicas ou profissionais. O presente artigo se detém sobre dois desafios fundamentais: a discussão sobre a epistemologia e a pedagogia subjacente às chamadas disciplinas técnicas ou profissionais e o necessário enfrentamento das mudanças do mundo do trabalho.

Palavras-chaves: Educação Profissional e Tecnológica. Epistemologia das disciplinas técnicas e profissionais. Desafios da formação docente. 


\section{Epistemological and pedagogical aspects of professional and technological education: implications for teaching practice}

The unprecedented expansion in professional and technological education in recent decades has not been accompanied by sufficient training teacher courses. Thousands of professional have worked in this area, without any previous debate about vocational education characteristics and its implications for teaching practice. There is a consensus about the lack of specific teacher training, particularly for those who work in technical or professional subjects. This article focuses on two fundamental challenges: the discussion about epistemology and the pedagogy underlying the technical or professional disciplines; and the necessary confrontation of changes in the world of work.

Keywords: Professional and Technological Education. Epistemology of technical and professional disciplines. Challenges of teacher education.

\section{Aspects épistémologiques et pédagogiques de l'enseignement professionnel et technologique: implications pour la pratique de l'enseignement}

L'expansion sans précédent dans l'éducation professionnel et technologique a eu lieu au cours des dernières décennies n'a pas été accompagnée par des actions suffisantes à la formation des enseignants. Des milliers de nouveaux enseignants ne discutaient jamais sur les caractéristiques de l'enseignement professionnel et ses implications pour l'enseignement pratique. II y a un consensus sur le manque de formation spécifique des enseignants, en particulier pour ceux qui travaillent dans les disciplines techniques ou professionnelles.Cet article insiste sur deux défis majeurs: la discussion de l'épistémologie et de la pédagogie sous-jacente de las disciplines techniques ou professionnelles; et la nécessité de faire face aux changements dans le monde du travail.

Mots-clés: Éducation Professionnelle et Technologique. Épistémologie des disciplines techniques et professionnelles. Les défis de la formation des enseignants. 


\section{Aspectos epistemológicos y pedagógicos de la educación profesional y tecnológica: implicaciones para la práctica docente}

La expansión sin precedentes que se produjo en las últimas décadas en la educación profesional y tecnológica no fue seguido por las acciones suficientes para la formación del profesorado. Miles de profesionales han ejercido la enseñanza en este campo sin ningún debate previo acerca de sus características e implicaciones para la práctica docente. Existe un consenso acerca de la falta de formación específica de profesores, sobre todo para aquellos que trabajan en las llamadas disciplinas técnicas o profesionales. Este artículo trata acerca de dos desafíos fundamentales: la discusión de la epistemología y de la pedagogía que subyacen a la así llamada disciplinas técnicas o profesionales; y la necesidad de hacer frente a los cambios en el mundo del trabajo.

Palabras clave: Educación Profesional y Tecnológica. Epistemología de las disciplinas técnicas y profesionales. Desafíos de la formación del profesorado. 


\section{Introdução}

A expansão no número de cursos e instituições de educação profissional e tecnológica (EPT) nas últimas décadas tem mobilizado um número expressivo de profissionais com vistas à atuação tanto na docência, quanto na gestão e demais atividades administrativas e técnicas. Além dos docentes oriundos das várias áreas de formação, profissionais que desenvolvem diferentes atividades especializadas encontram nessas instituições um importante mercado de trabalho. Os dados dos censos da educação básica e superior realizados pelo Instituto Nacional de Estudos e Pesquisas Educacionais Anísio Teixeira (Inep) auxiliam a se ter uma ideia desse cenário.

Em 2005, foram contabilizados 3.230 (três mil duzentos e trinta) estabelecimentos de ensino com matrículas em cursos técnicos de nível médio. É importante destacar que esse número se refere principalmente a instituições com matrículas em cursos técnicos nas formas concomitante e subsequente ao ensino médio, uma vez que a oferta na forma integrada era ainda incipiente. Em 2015, foram registrados 8.040 (oito mil e quarenta) estabelecimentos de educação profissional, representando principalmente escolas com matrículas em cursos técnicos de nível médio nas diferentes formas de oferta.

No mesmo período, a quantidade de docentes na educação profissional mais que dobrou. Em 2005, foram registradas 59.687 (cinquenta e nove mil seiscentos e oitenta e sete) funções docentes. Em 2015, o número de professores foi de 138.584 (cento e trinta e oito mil quinhentos e oitenta e quatro). É importante chamar atenção para a mudança na forma de coleta de dados. Em 2005, foram computadas funções docentes e, em 2015, os profissionais em efetiva regência de classe na data de referência do Censo Escolar, sendo que, no total Brasil, os docentes são contados uma única vez, independente de atuarem em mais de uma região geográfica, unidade da federação, município ou tenham mais de uma escolaridade ou formação acadêmica.

Dos docentes atuantes em turmas de educação profissional em 2015, 106 (cento e seis) possuíam apenas o ensino fundamental, 13.811 (treze mil oitocentos e onze) o ensino médio e 124.667 (cento e vinte e quatro mil seiscentos e sessenta e sete) graduação. Dos profissionais com nível superior, 77.181 (setenta e sete mil cento e oitenta e um) possuíam alguma licenciatura. No que diz respeito à formação em nível de pós-graduação, foram contabilizados 52.239 (cinquenta e dois mil duzentos e trinta e nove) docentes com especialização, 15.853 (quinze mil oitocentos e cinquenta e três) com mestrado e 3.937 (três mil novecentos e trinta e sete) com doutorado.

A importância desse mercado de trabalho pode ser verificada também na educação 
superior. O censo de 2015 contabiliza a oferta de 6.618 (seis mil seiscentos e dezoito) cursos tecnológicos, que correspondem a praticamente $20 \%$ (vinte por cento) do total dos cursos nesse nível educacional.

No entanto, as ações de formação docente para a EPT não acompanharam a velocidade dessa expansão. Além da temática estar praticamente ausente nas licenciaturas em geral, são poucos os cursos específicos de licenciatura em EPT ou de pós-graduação lato sensu voltados à formação de especialistas nessa área. O tema está também ausente nas especializações em didática da educação superior. Na pósgraduação stricto sensu, são relativamente recentes as linhas de pesquisa e programas que se dedicam ao estudo dessa modalidade educacional, sendo ainda acanhado, na produção acadêmica brasileira, o debate sobre a formação docente na EPT.

Filósofos, músicos, físicos, geógrafos, pedagogos, assistentes sociais, psicólogos, advogados, educadores físicos, economistas, administradores, bibliotecários, cabeleireiros, cozinheiros, fisioterapeutas, técnicos agrícolas entre outros tantos profissionais de uma extensa lista têm ingressado nas chamadas instituições especializadas em educação profissional ou atuado em outros espaços em cursos designados como da EPT sem compreender exatamente o que há de específico em tais instituições e cursos.

No senso comum, instituições de ensino e cursos no âmbito da EPT são normalmente denominados como profissionalizantes. Os lugares-comuns são bons pontos de partida para o desenvolvimento de debates mais profundos em direção a uma consciência mais crítica ou, em termos freirianos, são bons estímulos para a curiosidade epistemológica. Nesse caso, a ideia mais ou menos vaga de profissionalização pode ser um fértil nascedouro de questionamentos acerca dos modos como se dá a formação do ser profissional, considerando as distintas formas de lidar com o conhecimento nas várias profissões e especialidades técnicas.

Considerando que essas distintas formas de lidar com o conhecimento produzem diferentes identidades e perspectivas epistemológicas, quais seriam as implicações para a prática docente? Tais reflexões levam, ainda, a indagar se a formação docente, da forma como é realizada hoje, responde, adequadamente, às especificidades do exercício da docência na EPT ante às demandas do mundo do trabalho contemporâneo.

Foi este o caminho escolhido para o desenvolvimento das reflexões apresentadas neste artigo que se debruça sobre os desafios da formação docente na EPT. O presente texto deriva, principalmente, dos debates desenvolvidos na palestra "Desafios para a formação docente na educação profissional e tecnológica" e na oficina "A epistemologia da educação profissional e tecnológica e suas consequências 
para a prática docente", que tiveram lugar no XI Congresso Internacional de Tecnologia da Educação, realizado em setembro de 2016, em Recife, PE.

As reflexões desenvolvidas se amparam em certo consenso quanto à inexistência de formação específica para os saberes da docência por parte significativa de professores da EPT, em particular os oriundos das áreas técnicas. Tal formação tem sido comumente denominada de complementação pedagógica e direcionada principalmente aos bacharéis.

A hipótese que orienta o estudo é a de que tanto a formação inicial em licenciaturas quanto a continuada em cursos de complementação pedagógica não são adequadas, não respondendo às especificidades da docência em EPT. Tal inadequação se daria pela ausência de discussões sobre a epistemologia da EPT e a pedagogia subjacente às disciplinas profissionais ou técnicas.

Nesse sentido, o objetivo central do texto é refletir sobre aspectos da epistemologia da EPT e algumas de suas consequências para a prática docente. Especificamente, busca-se refletir acerca:

- dos modos de conhecer nos diferentes ofícios, profissões e especialidades técnicas e seus impactos na construção da identidade profissional, das representações para ação, dos critérios de atribuição de significado e valor aos saberes;

- das especificidades dos processos de aprendizagem no ambiente escolar e no trabalho;

- dos impactos dessas caraterísticas epistemológicas para a pedagogia das disciplinas técnicas-profissionais e para a atuação na EPT de forma geral;

- de modelos de formação que respondam adequadamente às características do mundo do trabalho contemporâneo e às demandas econômicas, sociais, ambientais contemporâneas no país e no mundo.

As principais questões que orientam tais reflexões podem ser expressas nos seguintes termos: Há especificidades na formação do docente da EPT?Como e onde os professores da EPT adquirem os saberes da docência? Quais são os saberes mobilizados pelos docentes em sua prática profissional? Que modelo(s) de formação responderia(m) adequadamente a essas questões? 
Considerados os objetivos propostos e as questões em debate, o presente texto foi estruturado em torno de dois desafios compreendidos como fundamentais. $O$ primeiro diz respeito à necessidade de compreender a epistemologia da EPT e suas consequências para a prática docente. $O$ segundo desafio, estreitamente relacionado ao primeiro, é o da necessária mudança na visão de ciência e tecnologia dominantes, para se pensar uma formação docente capaz de responder aos desafios do mundo do trabalho e suas mudanças.

\section{Perspectivas epistemológicas e identidades profissionais}

No verbete Formação profissional do Dicionário de trabalho e tecnologia, Cattani e Ribeiro (2011) a definem como uma dimensão do viver em sociedade em que os processos educativos destinam-se ao desenvolvimento de saberes estéticos, técnicos e científicos, tendo em vista a atuação na esfera produtiva. Nessa definição, os autores apontam para o fato de a formação do ser profissional ocorrer em múltiplos espaços sociais e se caracterizar por sua finalidade: a atuação na dimensão produtiva do viver em sociedade.

De fato, a formação profissional do trabalhador é impactada por conhecimentos, valores, habilidades, entre outras qualidades estruturadas nas diferentes esferas da vida social. Entre essas esferas, a escolar e a laboral se apresentam como espaços formativos particularmente importantes na constituição do ser profissional. Esses espaços possuem finalidades, características e racionalidades distintas, mas ambos são impactados por visões de mundo em disputa.

$\mathrm{Na}$ análise de elementos históricos e conceituais da EPT, Carvalho, Silva e Araújo (2016) abordam a multiplicidade de denominações utilizadas como referência à formação profissional. As autoras buscam destacar como, na legislação brasileira e na literatura especializada, os sentidos atribuídos aos termos profissional, técnico, tecnológico (e suas variantes) vinculam-se às concepções predominantes em diferentes períodos ou contextos históricos. Os usos de um ou outro termo refletem, em certa medida, os dissensos e disputas em torno desse campo, classificado na legislação como modalidade de ensino da educação básica e superior.

As disputas sobre nomenclaturas e conceitos constituem uma das partes mais visíveis desse campo de investigação que se mostra tão complexo como o próprio trabalho, como atividade humana em constante devir. Para os profissionais que exercem a atividade docente na EPT os desafios são múltiplos face à complexidade desse 
território, arena de profundas disputas, repleta de conflitos e contradições.

Como dito anteriormente e em consonância com o apontado por Machado (2008) e por Carvalho e Souza (2014), a carência de debate sobre a formação docente na EPT, na produção acadêmica brasileira, agrava o sentimento de desamparo entre professores que buscam novas referências para sua prática. Nesse cenário, apreender a epistemologia da EPT e suas consequências para a prática docente se constitui como um desafio fundamental.

Diferentes estudos no campo da ergonomia do trabalho de matriz francófona tais como Guérin e outros (2001) e Ferreira (2012) evidenciam o fato de o trabalho conformar os indivíduos ao mesmo tempo em que é forjado por estes. Seguindo a abordagem da ergonomia da atividade dentro de uma perspectiva histórico-cultural, é possível perceber como a atividade humana de trabalho nos diferentes ofícios, profissões e especialidades técnicas vai delineando modos próprios de lidar com o conhecimento, estruturando perspectivas epistemológicas e identidades profissionais.

caminho ora proposto toma por ponto de partida a indagação sobre o como se dá a formação do ser profissional na atividade de trabalho, buscando, entre outros aspectos, identificar critérios coletivos e pessoais de validação e de negação de saberes e os modos de compartilhamento, estruturação e aquisição do conhecimento em função dos graus de experiência e amadurecimentos dos operadores.

Esse olhar sobre a atividade de trabalho tem por objetivo fornecer elementos para compreender em que medida os espaços institucionais de ensino lidam com tais traços históricos e culturais das profissões, assimilando, negando e reconfigurando seus diferentes aspectos. Nesse horizonte, o estudo realizado por Richard Gagnon (2010) acerca da epistemologia das disciplinas técnicas e profissionais aponta para um caminho interessante.

O autor propõe o exame dos modos como se estruturam e se articulam os conhecimentos nas várias profissões, localizando-os em relação às práticas e formas de conhecer dos ofícios tradicionais e das profissões surgidas da tecnociência ou profundamente transformadas por ela. Ele identifica nessas dinâmicas a existência de distintas perspectivas de reconhecimento e legitimação do conhecimento, fundamentando sua análise na noção de saber significativo.

Gagnon desenvolve sua proposição tomando como referência o trabalho de David Kolb sobre estilos de aprendizagem. Kolb (1984) busca identificar as diferentes maneiras de aprender das pessoas adultas em função de como percebem e processam a realidade. Seu modelo analítico se baseia na compreensão de que as informações são 
captadas de formas distintas pelos indivíduos. Nessa direção, distingue inicialmente, dois grupos: o dos indivíduos mais empíricos, que captam a realidade pela experiência, e daqueles mais teóricos, que buscam abstrações e modelos explicativos.

Em decorrência dessas características básicas, os indivíduos do primeiro grupo tenderiam a ser mais empáticos e a realizar várias tarefas simultaneamente. Os do segundo grupo, por sua vez, tenderiam a se concentrar em uma única tarefa. Com base nessa linha de raciocínio, o modelo teórico é organizado em torno de dois eixos.

O eixo horizontal representa a posição epistemológica do sujeito entre a experimentação ativa e a observação reflexiva. $O$ eixo vertical representa maior ou menor tendência a aprender a realidade pela experiência concreta ou pela conceitualização abstrata. Dessa forma, de acordo com a localização do sujeito em função dos modos como percebe e processa a realidade, torna-se possível comparar características comuns. O modelo proposto utiliza quatro estilos básicos de aprendizagem ilustrados na figura 1: adaptadores, divergentes, assimiladores e convergentes.

Figura 1: Estilos básicos de aprendizagem de Kolb (1984)

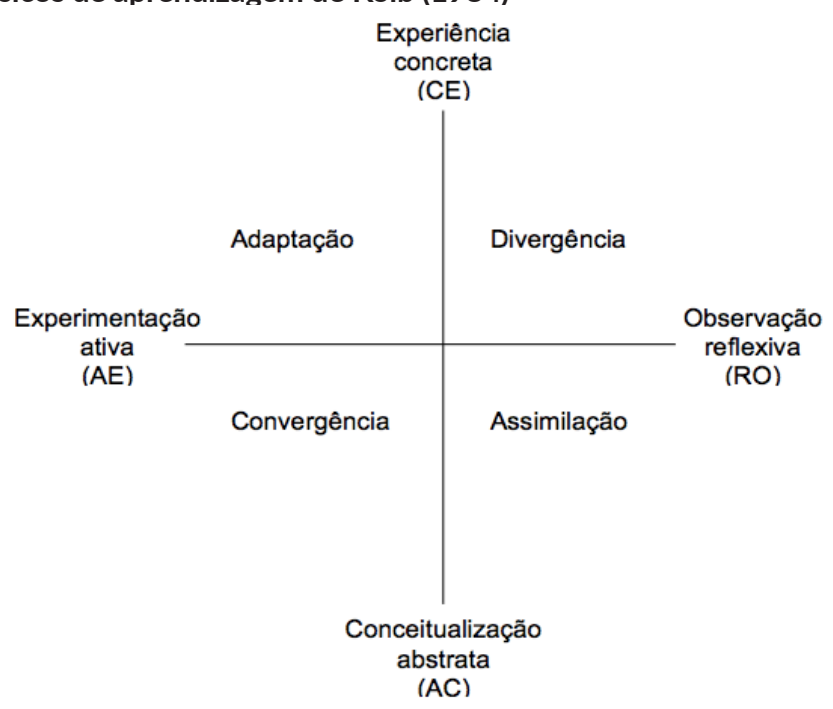

Fonte: Adaptado de Kolb (1984)

A breve apresentação sobre os estudos de Kolb tem por objetivo apenas situar o trabalho de Gagnon, uma vez que, na análise das perspectivas epistemológicas nas 
diferentes profissões, utiliza-se de recurso similar, optando por um modelo teórico em que são considerados os polos da tradição, da tecnociência, pessoas e coisas (figura 2).

Na proposição de Gagnon, o problema da atribuição de significado ao saber é visto tanto sob o prisma individual quanto sob a ótica social. Do ponto de vista do indivíduo, um saber é significativo conforme sua pertinência e validade no horizonte epistemológico pessoal. Socialmente, o significado está relacionado à pertinência e à validade desse conhecimento para o coletivo, em conformidade com a posição epistemológica do grupo, considerados seus interesses e modos de validação reconhecidos pela maioria.

Figura 2: Modelo de classificação das profissões e especialidades técnicas de Gagnon (2010)

Tradição

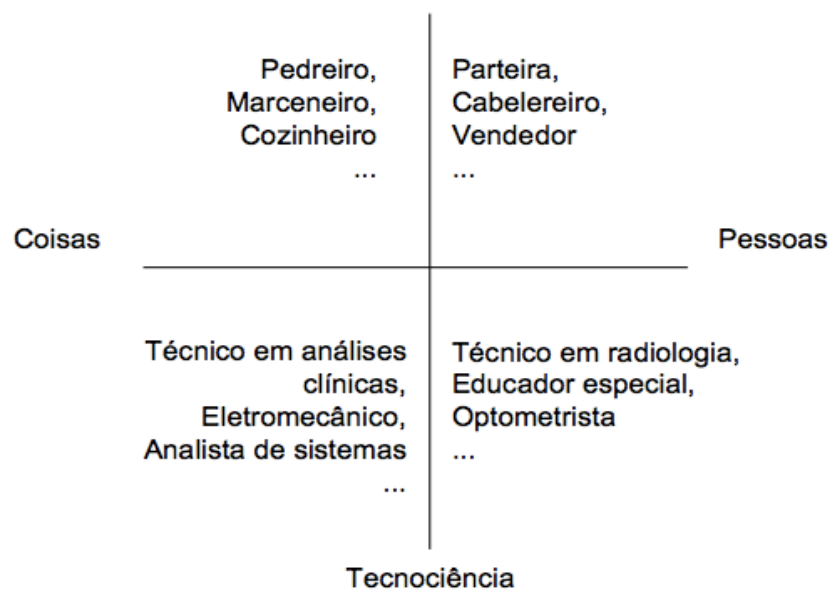

Fonte: Adaptado de Gagnon, 2010.

Em suas vivências laborais, os trabalhadores vão se imbuindo dos valores coletivamente compartilhados, porém, sob perspectivas diferentes. A autoridade do conhecimento, por exemplo, é vista de forma distinta se tomada sob a ótica da tradição ou da tecnociência. Nas profissões e especialidades técnicas com maior identidade com ofícios tradicionais, tal autoridade decorre, essencialmente, de um empirismo prolongado. Nas profissões nascidas da tecnociência ou profundamente modificadas por ela, reside principalmente no rigor do uso do método científico. 
A questão da tradição também é abordada por Polanyi (2005) em suas formulações sobre o que chama de pensamento pessoal nas ciências. Segundo o autor, na tradição estão presentes os elementos necessários ao compartilhamento dos saberes tácitos. Ele a define como um sistema de valores extrínseco ao sujeito. Esse sistema se configura como um conjunto de prescrições, normas, princípios, padrões de ação que existe antes mesmo do sujeito e orienta o comportamento pessoal e as expectativas em relação a outras pessoas.

Tal sistema de valores serve, assim, como referencial de validação do conhecimento. Segundo Polanyi, são critérios objetivos por estarem referenciados em um sistema de normas externo ao sujeito. Essa linha de raciocínio leva-o a falar de um conhecimento pessoal objetivo e não de subjetividade no pensamento científico. A tradição é assim entendida em um horizonte mais amplo.

Ao reconhecer a autoridade das referências contidas nesse sistema de valores, o sujeito passa a assumi-las na atribuição de significado pessoal àquilo que conhece. $\mathrm{Na}$ tradição se faz presente o que não está dito, mas que é compartilhado pelos membros de um grupo e se faz presente em sua identidade. Polanyi busca evidenciar a impossibilidade da absoluta especificação da arte presente nos ofícios e na própria ciência, em função de não existirem prescrições suficientes e adequadas para sua transmissão. Dada tal condição, o exemplo e o convívio são tomados como elementos essenciais para a continuidade da tradição, sendo a noção de autoridade central nesse processo.

No modelo proposto por Gagnon, a localização em relação ao eixo coisas - pessoas busca indicar se o trabalho está relacionado mais com coisas ou com seres humanos. Esses polos, coisas e pessoas, igualmente representam conjuntos de valores que estabelecem os significados e a validade de um saber. Trabalhar mais com pessoas pode favorecer saberes relativos ao cuidado, à atenção, ao convívio, entre outros. Enquanto se ocupar mais com coisas pode indicar a valorização de saberes vinculados à precisão técnica, ao raciocínio lógico e assim por diante.

A influência da tradição em um ofício é determinada pelas pessoas e instituições que continuam dando forma a este, encarnando sua prática. São valorizados os sentimentos de filiação e de responsabilidade sobre a preservação desses saberes e sua transmissão às gerações futuras, implicando a consideração à repetição, à reprodução e ao dever de memória.

A tradição, em certos ofícios, tem tanto vigor que contém a totalidade de seus próprios modos de reprodução, torna-se processo, ditando sua própria criação. A gestão epistemológica implícita à aprendizagem, fundamentada na tradição, 
constitui-se especialmente sobre a imitação e a experiência. A imitação é assumida e valorizada como recurso didático na relação entre discípulo e mestre, não somente para a assimilação da sequência de operações e gestos, mas principalmente para a compreensão do processo a partir de uma experiência pessoal orientada pela perspectiva do outro, muitas vezes com a adesão a suas ideias e atitudes.

Nas profissões mais próximas da tecnociência, as referências assumidas são constituídas, em grande medida, por valores que orientaram hegemonicamente a ciência moderna: a impessoalidade, a objetividade, o rigor metodológico. A gestão epistemológica subjacente à aprendizagem tecnocientífica, pressupõe que a atividade técnica se realiza a partir das ciências, com fundamento nos conhecimentos científicos, estruturados sobre conceitos e princípios claros, racionais e rigorosamente demonstrados empiricamente, Essas características apontam para abordagens nas quais predomina uma certa ideia de neutralidade, impessoalidade e a-historicidade, ao mesmo tempo em que são valorizados os atributos da racionalidade e da objetividade. Obviamente, os polos propostos pelo autor constituem um recurso didático para compreensão das formas predominantes de gestão epistemológica nos diferentes ofícios, profissões, ocupações. Esse recurso permite evidenciar características singulares que possibilitam tanto a realização de comparações entre ofícios quanto no espectro de um mesmo ofício.

O autor busca evidenciar algumas consequências pedagógicas decorrentes dessas diferentes formas de lidar com o conhecimento. Em sua opinião, tradição e tecnociência apresentam enfoques diametralmente opostos: Na tradição, o metódico e associativo busca a conformação das atitudes e dos comportamentos em uma linha behaviorista, sendo enfatizado o aprender a produzir e a reproduzir de forma a se alcançar um determinado resultado, mesmo que, de início, não se compreenda exatamente o processo. Na tecnociência, é o conceitual e hipotético que opera com as relações de causa e efeito, enfatizando a capacidade de análise.

É importante lembrar que qualquer dos métodos não ocorre de forma pura. Eles se mesclam em conformidade com as características do ofício, assim, mesmo em um curso bastante prático como o de auxiliar de cozinha, por exemplo, em que a imitação é tomada como um dos principais recursos didáticos, é possível verificar um certo grau de elaboração de hipóteses, a exploração da relação causa-efeito, entre outros recursos utilizados pelos formadores nas aulas e nas atividades desenvolvidas no restaurante-escola.

Geralmente, como é próprio da tradição, o processo se origina em uma situação concreta, por exemplo, uma receita que deve ser preparada nas condições estipuladas pelo formador. Nesse caso, os aprendizes mais experientes tendem a se sair melhor, 
evidenciando um conhecimento mais aprofundado em relação à manipulação dos ingredientes, ao uso dos instrumentos, ao tempo de cozimento, ao tempero, às técnicas empregadas etc.

Gagnon se refere a esse aspecto ao salientar que o aprendiz se reporta a um tipo de banco de dados da experiência, identificando os itens que mais se assemelharam àqueles utilizados em situações similares e reproduzindo operações, procedimentos e atitudes relacionados à resolução de casos do mesmo tipo. No enfoque fundamentado na tecnociência, uma ideia ou hipóteses deve ser submetida a deduções lógicas que levem a conclusões a serem comparadas entre si e entre outros enunciados, estabelecendo-se relações.

No ambiente escolar, a formação profissional orientada pela tradição tem como um de seus principais traços a intenção de reproduzir, o mais fielmente possível, o contexto do exercício do ofício considerado. No entanto, pode-se observar distinções claras nas formas como se processam as aprendizagens em cada um desses contextos: escola e trabalho. A simulação ou situação controlada realizada no meio escolar (ou em contexto de trabalho, mas no âmbito de um projeto pedagógico escolar) tem como pretensão propiciar algo próximo da experiência de trabalho com a reprodução de métodos e procedimentos colocados em prática.

$\mathrm{Na}$ atividade de trabalho propriamente dito, o contato com a realidade é direto, em sua totalidade subjetiva, trazendo sempre alguma novidade. A cada contato vive-se uma nova situação jamais idêntica a qualquer outra, mesmo que a diferença seja quase sempre imperceptível. É então edificada uma imensa memória constituída de feitos, eventos, associações, sensações, sentimentos, emoções. A experiência é vista, nessa perspectiva, como um processo e meio de construção de significado e sentido, portanto, elemento essencial para a aprendizagem.

Gagnon olha para as características epistemológicas dos ofícios procurando compreender os modelos pedagógicos convergentes. A noção de imitação não se refere à mera repetição, mas implica certo grau de vivência de uma experiência que se refere à situação escolar de simulação ou antecipação tendencial de uma situação de trabalho, e, no segundo caso, remete à situação de trabalho real. Em qualquer situação, há sempre uma reelaboração dos saberes pelo aprendiz, mas o meio (escola ou trabalho), e as relações sociais nele estabelecidas, modifica a perspectiva epistemológica. Na atividade de trabalho, o conhecimento é vivo, com toda a intensidade do trabalho real. Em um espaço formal de ensino, o conhecimento se encontra, por assim dizer, artificializado, mediatizado. Em outras palavras, no contexto de trabalho, o conhecimento é o próprio trabalho ao passo que, em um processo formal de ensino, o conhecimento é sobre o trabalho. 
Além das especificidades das relações de trabalho e das relações educacionais e do fato de o estudante não ser um aprendiz tradicional, Gagnon realça ainda outra questão no que diz respeito às aprendizagens ocorridas no interior das estruturas educativas instituídas. Nesses ambientes, o profissional responsável pela formação exerce uma segunda atividade, diferente daquela que ensina, eles imitam a prática do ofício ou da especialidade técnica que ensinam. Assim, sem se dar conta, os estudantes aprendem também a reproduzir modos de ensinar. Muitos dos que atuam no ensino profissional têm sua formação inicial na área profissional, não sendo tão rara a figura do professor leigo ou do instrutor.

Vários têm sua formação no próprio posto de trabalho, orientados por outros profissionais que atuaram como tutores. Parte daqueles que passaram por algum processo formativo formal o fizeram em cursos eminentemente práticos. Por isso, as referências das práticas pedagógicas desses docentes se encontram, fundamentalmente, no modelo de tutoria (mentoring). Esses profissionais desenvolvem competências pedagógicas empíricas enriquecidas por suas trajetórias pregressas como estudantes.

No entanto, devido à tendência de valorização, no meio escolar, do pensamento reflexivo, da compreensão que precede à ação, enfim, do método científico, a formação docente acima descrita é questionada quanto a sua suficiência e pertinência sob os argumentos de que lhe faltam fundamentos conceituais, psicológico, pedagógico e epistemológicos. Observa-se, pois, um choque de perspectivas, tanto no interior da escola quanto em sua relação com as aprendizagens do cotidiano de trabalho. Desse ponto de vista os saberes escolares são considerados proposicionais, na medida em que se referem a proposições logicamente conectadas, limitando-se a enunciar conteúdo. Esses saberes cristalizados não seriam, assim, suficientes para ensinar o trabalho dos ofícios.

A transformação do conhecimento profissional em conteúdo escolar introduz uma conexão abstrata em relação aos dados da experiência, promovendo o rompimento com a realidade concreta (GAGNON, 2010, p. 18). A tecnociência opera com modelos e teorias em que os seres e as coisas são substituídos por representações abstratas. Desenvolve-se um pensamento especulativo no qual a comprovação ou não de uma hipótese pode se desenrolar sem que ocorra qualquer modificação na situação concreta. Dá-se, assim, um choque entre as perspectivas epistemológicas da tecnociência e da tradição no interior da escola e, também, entre os enfoques do conhecimento escolar e os dados da experiência laboral.

As formulações apresentadas mostram que os modos de conhecer dos diferentes ofícios, profissões ou especialidades técnicas integram as vivências dos indivíduos ao 
mesmo tempo em que orientam a elaboração das representações mentais para ação. O sistema de valores a que se vincula o ofício, a profissão ou especialidade técnica é um forte componente do meio com o qual o indivíduo interage e, simultaneamente, um filtro por onde passam as formas de compreender e descrever o meio. Em outras palavras, esse sistema engendra uma certa identidade profissional na qual o sujeito se espelha e pela qual se orienta, contribuindo tanto para a perpetuação desse sistema quanto para sua transformação.

As considerações aqui apresentadas sobre as perspectivas epistemológicas dos diferentes ofícios, profissões ou especialidades técnicas e sobre as desconexões entre saberes escolares e da experiência trazem elementos tanto para a compreensão dos modos próprios desses profissionais lidarem com os diversos saberes no desenvolvimento de suas competências laborais, quanto para um exame mais atento das especificidades epistemológicas desses dois loci de formação: escola e trabalho. A tomada de consciência dessas especificidades se mostra, pois, como um desafio fundamental para a construção da prática docente em EPT.

\section{O mundo do trabalho e suas mudanças}

Um segundo desafio, estreitamente relacionado com o primeiro, é o da necessária mudança na visão de ciência e tecnologia dominantes para se pensar uma formação docente capaz de responder aos desafios do mundo do trabalho e suas mudanças.

Identifica-se consensualmente a informação, o conhecimento e as tecnologias de informação como elementos fundamentais da dinâmica da nova (des)ordem mundial. Da mesma forma, dentre as características mais importantes do novo padrão de acumulação, nota-se sempre a relevância e complexidade dos conhecimentos científicos e tecnológicos desenvolvidos e utilizados. O acesso a tais conhecimentos, assim como a capacidade de apreendê-los, acumulá-los e usá-los, são vistos como definindo o grau de competitividade e desenvolvimento de nações, regiões, setores, empresas e indivíduos.

Contudo, esse papel mais central e estratégico do conhecimento, a serviço da competitividade deve ser problematizado. O desenvolvimento científico, tecnológico e inovador nunca é neutro nem automático. Por mais óbvio que possa parecer o papel da ciência e tecnologia hoje, de forma alguma se deve descuidar do estímulo à continuidade dos processos de aprendizado e de desenvolvimento científico, tecnológico e inovador, tendo em vista não apenas as necessidades do crescimento econômico, mas particularmente do desenvolvimento social. 
O campo da formação profissional está se ampliando, abrangendo os trabalhadores ao longo de toda a sua vida ativa. Essa superação da educação como um momento específico e marco inicial na trajetória futura do trabalho, por uma educação que se torna uma necessidade constante e deve ser atendida periodicamente, mostra a importância de se implementar políticas de educação para o trabalho. Assumir esse papel estratégico, supõe que a formação para o trabalho considere o atual contorno da sociedade tecnológica e o surgimento de uma nova formação, permeada por novos modelos capazes de ultrapassar o tradicional debate que separa a formação integral da formação técnica.

Nesse sentido, é necessário inserir a produção científica e tecnológica em um contexto real, vinculado a necessidades sociais bem delimitadas.Assim, a formação profissional deve ser voltada para a resolução de problemas concretos e reais da humanidade e precisa estar inserida em projetos da sociedade, considerada em termos sociais e culturais.

Para garantir a coerência da educação para o trabalho, faz-se necessária a adoção de modelos didáticos que assegurem o desenvolvimento de saberes técnico-científicos, não apenas capazes de instrumentalizar o indivíduo para situar-se no mercado de trabalho e adaptar-se às suas constantes mudanças, mas também para comprazer-se na detenção de conhecimentos que aumentam sua dimensão humana e potencializam suas capacidades de interferir no meio em que vive (SANTOS, 2000).

Deve-se cuidar, portanto, do equilíbrio entre teoria e prática na abordagem curricular da formação para o trabalho. Isto implica o rompimento com a ideia de que o cidadão comum não pode participar e não tem acesso ao movimento científico e tecnológico. A instauração do novo modo de produção do conhecimento articula-se em torno do aumento da capacidade da sociedade para produzir e utilizar ciência e tecnologia, o que implica um maior compartilhamento do conhecimento e em uma reinvenção das relações educativas. Isso nos leva a outra questão, o da necessária mudança dos modelos teóricos e pragmáticos na formação profissional.

As relações educativas tradicionais têm suas bases alicerçadas em torno da continuidade e da natureza estática dos conhecimentos, sumariamente apresentados em materiais didáticos (livros, filmes, softwares) que perpetuam tais representações sociais junto aos professores em formação e em exercício. Relações educativas coerentes com as novas tendências deverão ser conduzidas na direção da inovação, do dinamismo do conhecimento e da ação docente, exigindo processos contínuos e continuados de aprendizagem. Esses modelos teóricos e empíricos são passíveis de diferentes articulações, leituras e aplicações, profundamente dependentes da dinâmica social - da qual todos nós fazemos parte. Isso nos leva ao problema das 
abordagens didáticas no ensino.

A abordagem tradicional de formação é de natureza condutivista, contempla cada "saber" ou "saber fazer" como algo que se pode adquirir com um treinamento específico proporcionado de fora (CARVALHO; GIL PEREZ, obra citada) e reprodutivista, voltadas para a transmissão sistemática, acrítica e estática dos conhecimentos. A nova formação acena para uma abordagem construtivista, que estabelece interações entre a formação geral e a formação técnica e que humaniza esse processo, evidenciando suas dimensões cognitivas e sociais. Tal abordagem só é possível com base em uma nova compreensão das relações entre a ciência, a tecnologia e a sociedade.

Toda formação científica alheia à sinergia existente entre estes três elementos é extemporânea. Da mesma forma, todo e qualquer modo de produção de conhecimentos científicos e tecnológicos alicerçado em indivíduos que não compreendem as inter-relações entre o científico, o tecnológico e o social, é nocivo e compromete o próprio desenvolvimento sustentável.

No modo tradicional de formação, tais relações não são percebidas claramente, resultando em uma abordagem dicotômica e dissociada, cujas repercussões nefastas podem ser constatadas com facilidade no mundo atual (degradação do meio ambiente, destruição da camada de ozônio, pobreza crônica, violência e caos urbanos, analfabetismo, etc.).

A passagem de um modelo de formação fundamentado em uma relação meramente extrativista para um modelo baseado em uma relação ecológica, sustentável, que considera o ser humano como parte indissociável de um processo complexo cujo desequilíbrio pode ser irremediável. Uma tal relação entre ciência, tecnologia e sociedade exige mudanças no modo de abordagem dos campos do conhecimento.

É importante considerar a necessária congruência entre diferentes campos de saber, o que afeta consideravelmente toda iniciativa de educação para o trabalho. No entanto, sabemos que o estabelecimento de ligações entre campos de conhecimentos distintos ainda é um enigma, com raras incursões de sucesso. De fato, a interdisciplinaridade é apontada como crucial para a adequação da formação às novas demandas sociais em termos de educação formal e não-formal, mas suas dimensões ainda não foram completamente compreendidas, justamente por causa da dicotomia cristalizada entre ciência e tecnologia.

Uma questão em aberto é, portanto, como articular o saber técnico por meio da interconexão com outros saberes, permitindo, sobretudo, a reinvenção dos saberes, a construção e a reconstrução contínua de conhecimentos, o abandono de uma 
perspectiva unidisciplinar, mais próxima das premissas da formação tradicional, para uma perspectiva transdisciplinar, mais adequada a uma nova formação. No entanto, tal articulação entre os diferentes saberes exige a percepção sensível da pluralidade de espaços formativos.

A passagem do unidisciplinar para o transdisciplinar implica uma diversificação de espaços de interação com conhecimentos antes concentrados unicamente na escola. A sociedade tecnológica abre espaços para que conhecimentos formais possam ser construídos em diferentes locais, inserindo a educação para o trabalho em uma rede de formação altamente integrada com o meio social e suas diferentes instâncias. Volta-se, assim, para o problema da necessária mudança nas representações acerca da ciência e da tecnologia.

O combate ao hermetismo na formação profissional e na compreensão da ciência e da tecnologia é um aspecto essencial. Ele implica a modificação de posturas, arraigadas e transmitidas por meio de um círculo vicioso. Seria importante que o novo modelo fosse construído com base em uma maior abertura para a compreensão do empreendimento científico e tecnológico da humanidade, do qual somos todos herdeiros, para uma maior proximidade com questões ligadas a esses campos de conhecimento e com a ideia de que todo e qualquer conhecimento está sempre em processo de construção, seja ele coletivo ou individual.

A mudança na compreensão da função social da ciência e da tecnologia exige uma nova postura por parte dos docentes da formação profissional com relação ao papel do conhecimento científico e tecnológico na sociedade. Perceber a ciência e a tecnologia como sendo produtoras de respostas prontas e indiscutíveis aos problemas sociais corresponde a uma visão hermética que dissocia o fator humano do modo de produção vigente. O novo modelo deve se articular com base em uma compreensão distinta da função social da ciência e da tecnologia, encontrando nos problemas sociais a fonte e a inspiração do desenvolvimento científico e tecnológico.

Da mesma forma como não há conhecimento estático e construído de antemão, não poderia haver respostas definitivas e incontornáveis aos problemas sociais. Enfim, quaisquer que sejam as considerações que permitiriam prosseguir na tentativa de pensar os desafios da formação docente na EPT, é preciso admitir que os sinais indicadores da demanda por essa formação são bastante visíveis e a não se pode fugir da necessidade de debatê-la e de promovê-la. 


\section{Considerações finais}

São inúmeros os desafios da formação docente, seja para a educação básica ou superior (tão raramente discutida), seja para qualquer das modalidades de ensino. $\mathrm{Na}$ educação profissional e tecnológica a histórica escassez de ações voltadas à formação docente e a quase total ausência de um debate específico sobre a epistemologia da EPT e a pedagogia subjacente às disciplinas técnicas ou profissionais tem contribuído para um quadro de quase abandono desses profissionais que, não raro, possuem apenas sua experiência discente como referência para suas práticas pedagógicas.

A inédita expansão ocorrida nas últimas décadas tem contribuído para reacender o tema que carece de debates densos acompanhados de uma produção acadêmica consistente, de forma a produzir um referencial adequado para novos modelos de formação docente na EPT.

Orientado pela hipótese de que tanto a formação inicial em licenciaturas quanto a continuada em cursos de complementação pedagógica não são adequadas, não respondendo às especificidades da docência em EPT, este estudo se deteve em dois desafios: a necessária compreensão que as identidades profissionais operam com perspectivas epistemológicas distintas, com consequências para a prática docente e que as mudanças ocorridas no mundo do trabalho, em particular no que diz respeito à relação entre ciência, tecnologia e sociedade, devem conduzir a novos modelos e práticas.

Nesse segundo grupo, procurou-se ressaltar que as relações educativas coerentes com as novas tendências deverão passar de um modelo estático, baseado na continuidade, a um dinâmico, baseado na inovação, com consequentes alterações nas abordagens didáticas, nas formas de tratamento dos campos do conhecimento, e na compreensão da função social da ciência e da tecnologia.

O caminho é longo e são inúmeros os questionamentos, poucas as pistas e ainda mais raros os consensos. No entanto, acredita-se que, com o enfrentamento do problema em um debate mais profundo, seremos capazes de pensar uma formação docente coerente com os desafios do mundo do trabalho e suas mudanças. 


\section{Referências}

BROUGÈRE, Gilles; ULMANN, Anne-Lise (orgs.). Aprender pela vida cotidiana. Campinas: Autores Associados, 2012.

CARVALHO, Olgamir Francisco.; LACERDA, Gilberto. Dualismoversus congruência: diálogo entre o novo modelo brasileiro para a formação profissional e o modelo didático ESC (Experiencial, Científico e Construtivista). In: MOLL, Jaqueline (Org.). Educação profissional e tecnológica no Brasil contemporâneo: desafios, tensões e possibilidades. Porto Alegre: Artmed, 2010.

CARVALHO, Olgamir Francisco; SILVA, Caetana Juracy Rezende; Araújo, Mariângela. Educação Profissional e Tecnológica: elementos históricos e conceituais In: Educação Profissional e Tecnológica: elementos históricos e conceituais. Brasília: Editora UnB, 2016, p. 306 - 344.

CARVALHO, Olgamir Francisco; SOUZA, Francisco Heitor Magalhães. Formação do docente da Educação Profissional e Tecnológica no Brasil: um diálogo com as Faculdades de Educação e o Curso de Pedagogia: Educação e Sociedade, Set 2014, vol. 35, No 128, p. 883-908. ISSN 0101-7330

CATTANI, Alberto David; RIBEIRO, Jorge Alberto Rosa. Formação profissional. In: CATTANI, Alberto David; HOLZMANN, Lorena (Org.). Dicionário de trabalho e tecnologia. 2a ed. revista e ampliada Porto Alegre: Zouk, 2011. p. 203-209.

FERREIRA, Mário César. Qualidade de vida no trabalho: Uma abordagem centrada no olhar dos trabalhadores. 2a ed. Brasília, DF: Paralelo 15, 2012.

GAGNON, Richard. Epistemología de las disciplinas profesionales y técnicas. In: Linhas Críticas, Brasília, DF, v.16, n. 30, jan./jun. 2010. p. 5-26.

GUÉRIN, François et al. Compreender o trabalho para transformá-lo: A prática da ergonomia. São Paulo: Blücher, 2001.

INSTITUTO NACIONAL DE ESTUDOS E PESQUISAS EDUCACIONAIS ANÍSIO TEIXEIRA. Sinopses Estatísticas da Educação Básica 2005 a 2015. Brasília: Inep, 2007, 2008, 2009, 2010, 2011, 2012, 2013, 2014, 2015, 2016, 2017. Disponíveis em: <http://portal.inep.gov.br/web/guest/sinopses-estatisticas-da-educacaobasica $>$.

Sinopses estatísticas da educação superior 2015 - graduação. Brasília: Inep, 2016. Disponível em: < http:// portal.inep.gov.br/web/guest/ sinopses-estatisticas-da-educacao-superior $>$. 
KOLB, David A.Experiential learning: Experience as the source of learning and development. New Jersey: Prentice-Hall, 1984.

MACHADO, Lucília. Diferenciais inovadores na formação de professores para a educação profissional. Revista Brasileira da Educação Profissional e Tecnológica, Brasília, v. 1, n 1, 2008.

POLANYI, Michael. Personal Knowledge - Towards a Post-Critical Philosophy. London: Routkedge, 2005.

SILVA, Caetana Juracy Rezende. Do saber ao sabor: estudo da relação entre saberes tácitos e explícitos expressos nas competências laborais de cozinheiros em situação de trabalho. Doutorado em Educação. Brasília: UnB, 2016.

Recebido em fevereiro de 2017

Aprovado em abril de 2017

Caetana Juracy Rezende Silva é Doutora em Educação pela Universidade de Brasília (FE/UnB-2016).Técnica em Assuntos Educacionais do Ministério da Educação. Email: caetanarezende@gmail.com

Olgamir Francisco de Carvalho é doutora em Educação pela UNICAMP- Campinas. É professora associada da Faculdade de Educação da Universidade de Brasília.

Email: olgamirc@gmail.com 